\title{
AFM study on the adsorption and aggregation behavior of dissolved humic substances on mica
}

\author{
GE Xiaopeng ${ }^{1}$, ZHOU Yanmei ${ }^{2}$, LÜ Chunhua ${ }^{1} \&$ TANG Hongxiao ${ }^{1}$ \\ 1. State Key Laboratory of Environmental Aquatic Chemistry, Research Center for Eco-Environmental Sciences, Chinese \\ Academy of Sciences, Beijing 100085, China; \\ 2. School of Civil Engineering \& Architecture, Beijing Jiaotong University, Beijing 100044, China \\ Correspondence should be addressed to Tang Hongxiao (email: hxtang135@vip.sina.com.cn)
}

Received June 2, 2004; accepted June 15, 2005

\begin{abstract}
Humic substances constitute the major organic fractions of soils, sediments and natural waters, and play a dominant role in the binding, mobilization, transport and ultimate fate of organic contaminants in subsurface systems. In this paper, two humic acid samples, Guanting and Tianjin, with different origin and chemical compositions have been investigated with AFM imaging for their adsorption and aggregation behaviors on mica. While the Tianjin humic sample is found to form small spheres with 250 to $330 \mathrm{~nm}$ in diameter at lower concentrations, irregular loop-chain assemblies of hundreds of nanometer in diameter with the chain width of about $40 \mathrm{~nm}$ are dominant for the Guanting humic sample, which may attribute to the more polar aliphatic fractions in the chemical composition in the latter. The heterogeneous and polydisperse nature of humic substances with multiple structural features, such as sponge-like structures, perforated sheets, aggregate of spheres, branches and chain-like assemblies etc., is apparent at higher concentrations for both humic samples, showing morphologically new evidence for the dominant view of the humic dual-mode sorption model. With naphthalene introduced, the assemblies of Guanting humic substances clearly become more compact with significantly narrowed branches and less porous the perforated sheet-like structures. It is indicative of that smaller nanometer scale rings present along the perforated assemblies could potentially represent hydrophobic domains, which may facilitate the adsorption and aggregation of naphthalene onto the natural particle surfaces and therefore lead to an important role of dissolved humic substances in the sorption of environmental pollutants.
\end{abstract}

Keywords: atomic force microscopy (AFM), dissolved humic substances, morphology, aggregation, adsorption.

Humic substances (HS) are a category of naturally occurring, biogenic, heterogeneous organic materials found in or extracted from soils, sediments, and natural waters that can generally be characterized as being yellow-to-black in color, of highly variable relative molecular masses, and refractory ${ }^{[1,2]}$. Derived from a variety of organic precursors (plant biopolymers such as lignin etc.), plant residues and animal debris via both transformation and synthesis processes ${ }^{[3]}$ under the profound geochemical alteration, including the microbiological and chemical degradation, sedimentation and diagenesis as well, humic substances com- 
prise highly complex composites of partially or completely degraded biomolecules, carbohydrates, lipids, and proteins etc. However, they cannot be classified into any of the normal, easily defined categories of discrete materials such as proteins, polysaccharides, and polynucleotides. As the major organic constituents of soils, sediments and waters, humic substances are ubiquitous in all terrestrial and aquatic environments. They can form molecular aggregates, dispersed in different colloidal states in solution or deposited on mineral surfaces ${ }^{[4,5]}$, and therefore, strongly influence a wide range of environmentally important processes. For example, they may modify the chemical speciation of trace metals, stabilize inorganic colloids via adsorption $^{[6,7]}$, and significantly impact the fate and transport of hydrophobic organic pollutants in subsurface systems ${ }^{\left[{ }^{8-16]}\right.}$. A better understanding of their morphology and the underlying adsorption and aggregation processes is therefore of fundamental importance.

Humic macromolecules have been described as flexible linear chains with a polyelectrolytic character ${ }^{[17]}$ or as random coils that could form fairly compact spheres ${ }^{[18]}$ for the theoretical conceptual model. Nevertheless, a precise description of their size, shape and structure remains difficult because of the complex, heterogeneous and polydisperse nature of the humic substances. In this context, a lot of physical instruments and techniques have been exploited for the structural characterization of humic substances, including diffusion coefficient measurement ${ }^{[18,19]}$, luminescence spectroscopy (pyrene fluorescence probe etc. ${ }^{[20]}$, Size-Exclusion Chromatography (SEC) ${ }^{[3]}$, Cross Polarization Magic Angle Spinning carbon-13 Nuclear Magnetic Resonance (CPMAS ${ }^{13} \mathrm{C}-\mathrm{NMR}{ }^{[21-23]}$, Infrared (IR) analysis, and microscopic observation techniques like Scanning Electron Microscopy $(\mathrm{SEM})^{[21,24]}$ and Transmission Electron Microscopy (TEM) etc. For example, Stevenson and Schnitzer ${ }^{[25]}$ performed TEM analysis on dried HS samples and showed that depending on the HS concentration their structures change from spheroids with dimensions in the nanometer range at low concentrations to chainlike structure or flattened linear fibers and to perforated sheetlike assemblies at higher HA concentrations. More recently, atomic force microscopy (AFM) has been used for observation on the morphology of humic substances. Compared with other microscopies (SEM and TEM), AFM offers more flexibility in sample preparation (no need for dehydration, embedding, and coating etc.), three-dimensional images and in some cases better image resolution ${ }^{[26]}$, opening up an excellent opportunity for probing the structure and sorption behavior of natural particles and the associated humic substances. Heil and Sposito ${ }^{[27]}$ provided differences in AFM images of surface topography between the Handford soil colloids and the specimen illite particles to show visual evidence of organic coatings on the particles in the flocculation process of illitic soil colloids. Recently, Gerin and Dufrêne ${ }^{[28]}$ developed a procedure for probing the native surface structure of natural soil particles and characterized the properties of the adsorbed organic matter by combining AFM imaging and X-ray photoelectron spectrometry (XPS) analysis. A few reports have also described the use of AFM to characterize the structure of humic substances on mica after isolation from water streams and soils ${ }^{[29-36]}$. Maurice et al. ${ }^{[29,30]}$, for example, have imaged aggregate structures of humic substances in aqueous solutions, and reported small spheres (10-50 $\mathrm{nm})$ and "sponge-like ring structures". Wilkinson et $a l .^{[31,32]}$ performed both transmission electron and atomic force microscopy imaging on the freshwater colloidal organic matters and investigated the effects of solution $\mathrm{pH}$ and ionic strength on the size and conformation of two different HS on mica. Plaschke et $a l .^{[33-35]}$ performed in situ Fluid-AFM imaging on the sorbed humic acid colloids and investigated the influence of different $\mathrm{pH}$ conditions and $\mathrm{Eu}(\mathrm{III})$ ions on the agglomeration of humic acid. Liu et al. ${ }^{[36]}$ compared the thickness of adsorption layers obtained by AFM imaging for the two different sample preparation methods of freezing and air-drying. Liu et $a l .^{[37]}$ investigated the effect of substrate with different characteristics on the composition and amount of extracellular polymer substances (EPS) in activated sludge and provided SEM and AFM images of the EPS morphology. In this study, AFM is employed to further investigation of the aggregate structures of humic substances on mica in order to reveal the possible mechanism of humic substances in modifying the sorption behavior of hydrophobic organic contaminants onto the natural particles. Two humic acid sam- 
ples of Guanting and Tianjin with different origin and chemical composition have been investigated and naphthalene is introduced into the Guanting sample solution to show the structural changes during their interfacial adsorption processes.

\section{Experimental}

\subsection{Materials and instrumentation}

Ultrapure deionized water (Resistivity: $18 \mathrm{M} \Omega / \mathrm{cm}$ ) was used through all the experiments; chemical reagents used were all of analytical grade; nitrogen gas was of analytical pure.

(i) Humic substances and their characteristics.

Two humic acid (HA) samples were investigated for this study. One was a commercially available HA manufactured in Tianjin. The other was extracted from the sediment collected from the Guanting Reservoir, one of the major natural potable water resources near Beijing. It was operated according to the extraction and purification procedure given by the International Humic Substances Society (IHSS) ${ }^{[38]}$, which is shown in the following.

Appropriate portions of sediment were immersed in $0.1 \mathrm{~mol} / \mathrm{L} \mathrm{NaOH}$, a nitrogen flow was introduced into the solution for $1 \mathrm{~h}$. After purging the air with nitrogen the vessel was sealed and placed on a shaker for $12 \mathrm{~h}$. The suspension was separated by centrifugation and the supernatant was collected. The residual sediment was treated twice as described in the above. The combined supernatants were then adjusted to $\mathrm{pH}=2$ using $6 \mathrm{~mol} / \mathrm{L} \mathrm{HCl}$, and the solution was left overnight in order for the dissolved humic acids to release. After centrifugation, the supernatant was removed, and the obtained humic acid substances were rinsed with distilled water for 3 times followed by air-drying at ambient conditions.

The basic physicochemical properties of the two HA samples used are given in Tables 1 and $2^{[39]}$. The content of total organic carbon (TOC) and dissolved organic carbon (DOC) were determined on an Apollo-9000 TOC analyzer (Tekman-Dohrmann Co., U.S.A.). Potassium biphthalate (dried for $2 \mathrm{~h}$ before use) was used for the preparation of carbon standard solution. Elementary analysis was made on Vario-EL (Elementar Co., Germany) using the high temperature combustion method. Cation exchange capacity (CEC) was determined by $\mathrm{BaCl}_{2}$ method as described in the literature ${ }^{[40]}$. CPMAS ${ }^{13} \mathrm{C}$ NMR and ${ }^{1} \mathrm{H}$ NMR $\left(\mathrm{D}_{2} \mathrm{O}\right.$ as solvent) spectra were made on Avance-DPV $300 \mathrm{MHz}$ (Bruker Co., Germany. Measuring conditions: Probe, 4 $\mathrm{mm}$ in diameter; spinning rate, $13 \mathrm{kHz}$; contact time, 2 ms; delay, $1 \mathrm{~s}$; scanning width, $27 \mathrm{kHz}$ at $\delta=368$; Line broading, $100 \mathrm{~Hz}$ ) and Avance-DPX $500 \mathrm{MHz}$ (Bruker Co., Germany. Measuring conditions: Probe, 5 $\mathrm{mm}$ in diameter; delay, $1 \mathrm{~s}$; scanning width, $8012 \mathrm{~Hz}$ at $\delta=16$; line broading, $3.00 \mathrm{~Hz}$, Temperature, 295 $\mathrm{K})$, respectively.

(ii) Naphthalene stock solution. Aqueous solution of naphthalene was prepared by dissolving excess amount of solid naphthalene (with a purity of $99 \%$, purchased from Beijing, China) in a solution of 0.005 $\mathrm{mol} / \mathrm{L} \mathrm{CaCl}_{2}$ as a background electrolyte and 100 $\mathrm{mg} / \mathrm{L} \mathrm{NaN}_{3}$ to prevent bacterial growth. The mixture was subsequently treated by ultrasonic for $1 \mathrm{~h}$, shaken overnight on a reciprocating shaker, and then filtered using GF/F filter paper (Whatman Co., England) to remove any insoluble solute. The filtrate was finally

Table 1 The physicochemical properties of the two HA samples of Guanting and Tianjin

\begin{tabular}{|c|c|c|c|c|c|c|c|c|c|c|c|c|}
\hline \multirow[b]{2}{*}{$\begin{array}{l}\text { Humic } \\
\text { acid } \\
\text { sample }\end{array}$} & \multicolumn{4}{|c|}{ Elemental analytical results $(\mathrm{g} / \mathrm{g})(\%)$} & \multicolumn{5}{|c|}{ Analyzed by CPMAS ${ }^{13} \mathrm{C}$ NMR } & \multirow[b]{2}{*}{$\begin{array}{l}\text { TOC } \\
(\%)\end{array}$} & \multirow[b]{2}{*}{$\begin{array}{c}\mathrm{DOC}^{\mathrm{a})} \\
(\%)\end{array}$} & \multirow[b]{2}{*}{$\begin{array}{c}\text { CEC } \\
(\mathrm{cmol} \\
(+) / \mathrm{kg})\end{array}$} \\
\hline & $\mathrm{C}$ & $\mathrm{H}$ & $\mathrm{O}$ & $\mathrm{N}$ & $\begin{array}{c}\text { aliphatic C } \\
(\delta 0-100) \\
(\%) \\
\end{array}$ & $\begin{array}{c}\text { aromatic C } \\
(\delta 100-165) \\
(\%)\end{array}$ & $\begin{array}{c}\mathrm{COOH} \\
(\delta 165-185) \\
(\%)\end{array}$ & $\begin{array}{c}\text { carbonyl } \\
(\delta 185-220) \\
(\%)\end{array}$ & $\begin{array}{c}\text { hydrophobic } \\
\text { index }\end{array}$ & & & \\
\hline Guanting & 24.01 & 3.96 & 25.20 & 2.97 & 55.9 & 21.8 & 15.0 & 5.3 & 0.72 & 28.76 & 2.78 & 9.36 \\
\hline Tianjin & 62.53 & 4.80 & 32.34 & Null & 41.1 & 41.1 & 2.5 & 12.4 & 0.92 & 64.77 & 0.87 & 3.22 \\
\hline
\end{tabular}

a) Measured in the presence of $0.005 \mathrm{~mol} / \mathrm{L} \mathrm{CaCl}_{2}$ as the ion strength medium.

Table $2 \quad{ }^{1} \mathrm{H}$ NMR results for the dissolved fraction of the two HA samples of Guanting and Tianjin

\begin{tabular}{ccccc}
\hline \multirow{2}{*}{ Humic acid samples } & Aliphatic C & Aromatic C & Polarity & Hydrophobic index \\
& $(\delta 0-3.0)(\%)$ & $(\delta 6.5-8.5)(\%)$ & $(\delta 3.0-6.5)(\%)$ & 0.33 \\
Guanting & 24.6 & null & 75.4 & 84.1 \\
Tianjin & 15.4 & 0.5 & & 0.19 \\
\hline
\end{tabular}


transferred into a brown flask and tightly sealed with Parafilm immediately. The naphthalene stock solution was preserved in a refrigerator at $4^{\circ} \mathrm{C}$.

Freshly cleaved mica surface was used as substrate in all experiments. Natural muscovite slides with dimension of $2 \mathrm{~cm} \times 3 \mathrm{~cm}$ and $0.18-0.20 \mathrm{~mm}$ in thickness were first cut into approximately $10 \mathrm{~mm} \times 10 \mathrm{~mm}$ square pieces using a sharp, clean, single-edged razor blade. The mica pieces were then subjected to a through cleaning procedure which includes rinsing with distilled water to remove the small residual particulates created during the cutting process followed by a rinse with $95 \%$ ethanol and finally with absolute alcohol. The mica sheets were allowed to dry in air at ambient conditions in a clean room, and placed in a Petri dish for stock.

The atomic force microscope used was a NanoScope IIIa Multimode Scanning Probe Microscopy Instrument (Digital Instruments, Santa Barbara, CA) operating in air at room temperature with $50 \%-60 \%$ humidity. The images presented in this paper contain $256 \times 256$ data points (pixel resolution), acquired by using the retrace signal in the contact mode. The standard V-shaped silicon nitride $\left(\mathrm{Si}_{3} \mathrm{~N}_{4}\right)$ cantilevers (with integral tips, Model OTR8-35) of different stiffness and tip sharpness were used for imaging. Their nominal dimensions were $100-$ and $200-\mu \mathrm{m}$ in length and $0.8 \mu \mathrm{m}$ in thickness and possessed a spring constant ranging from 0.06 to $0.58 \mathrm{~N} / \mathrm{m}$. The scanning speed and the loop gain factors were varied during the imaging process. Line scan rates were typically set at about $2.5 \mathrm{~Hz}$ with other scan parameters such as Scan size, Set point, Integral gain, Proportional gain etc. varied and optimized. In order to avoid tip-related artifacts, imaging was performed with a minimal force and image features were reproduced before being accepted as representative. The prepared samples were investigated by AFM within a few hours after preparation. For each experimental condition, two mica sheets were prepared and at least three images were obtained for each mica sheet sample. Images were taken with online filtering and subsequently by flattening to remove the background slope. Using NanoScope Image analysis software, section analysis of images was conducted to measure the size of particles and their aggregates.

\subsection{Experimental methods}

Adequate amounts of HA samples were added to a mixture containing $0.005 \mathrm{~mol} / \mathrm{L} \mathrm{CaCl}_{2}$ and $100 \mathrm{mg} / \mathrm{L}$ $\mathrm{NaN}_{3}$, and the dispersion mixture was fully stirred overnight with a suspended magnetic stirrer while 0.1 $\mathrm{mol} / \mathrm{L} \mathrm{NaOH}$ was added drop-wise to maintain the alkalinity of the solution at $\mathrm{pH}=9$. After dissolution, the solution was left undisturbed for $24 \mathrm{~h}$ and the supernatant was filtered through the Millipore membrane. The solution was stored in a refrigerator at $4{ }^{\circ} \mathrm{C}$.

Two HA solutions with the concentration of 10 and $100 \mathrm{mg} / \mathrm{L}$ respectively (with $0.005 \mathrm{~mol} / \mathrm{L} \mathrm{CaCl}_{2}$ and $100 \mathrm{mg} / \mathrm{L} \mathrm{NaN}_{3}$ of presence, $\mathrm{pH}=8-9$ ) were made from dilution of the above stock solutions. Aliquots of the HA solution were then transferred into a $50 \mathrm{~mL}$ conical flask for the AFM sample preparation experiments. Mica was selected as the model surface to simulate the adsorption process of the dissolved humic substance on clay minerals. Before use of fresh basal-plane, surfaces were exposed by cleaving several upper layers with a scotch tape and then introduced into the HA solution. After stirring for $60 \mathrm{~h}$ on a shaker bed the mica was removed from the solution and gently rinsed by immersion into the deionized water (30 s) in order to remove any non-adsorbed humic acid and loosely attached substances. The mica was then allowed to dry in an enclosed Petri dish under ambient conditions and mounted on magnetized stainless steel stub by means of double-sticky tape for AFM observation.

For studying the adsorption of HA in the presence of naphthalene, in parallel with the HA control blank, a saturated solution of naphthalene was introduced into the HA dispersions before the mica sheet was immersed into the solution and operated in the same manner as described above for the adsorption and the AFM observation.

\section{Results and discussion}

Figs. 1 and 2 give a comparison of the morphological features of Guanting and Tianjin humic samples at the nano-scale level under different concentrations. It is shown that irregular loop-chain assemblies of hundreds of nanometer in diameter with doped particulates are dominant for the Guanting sample at $10 \mathrm{mg} / \mathrm{L}$, 

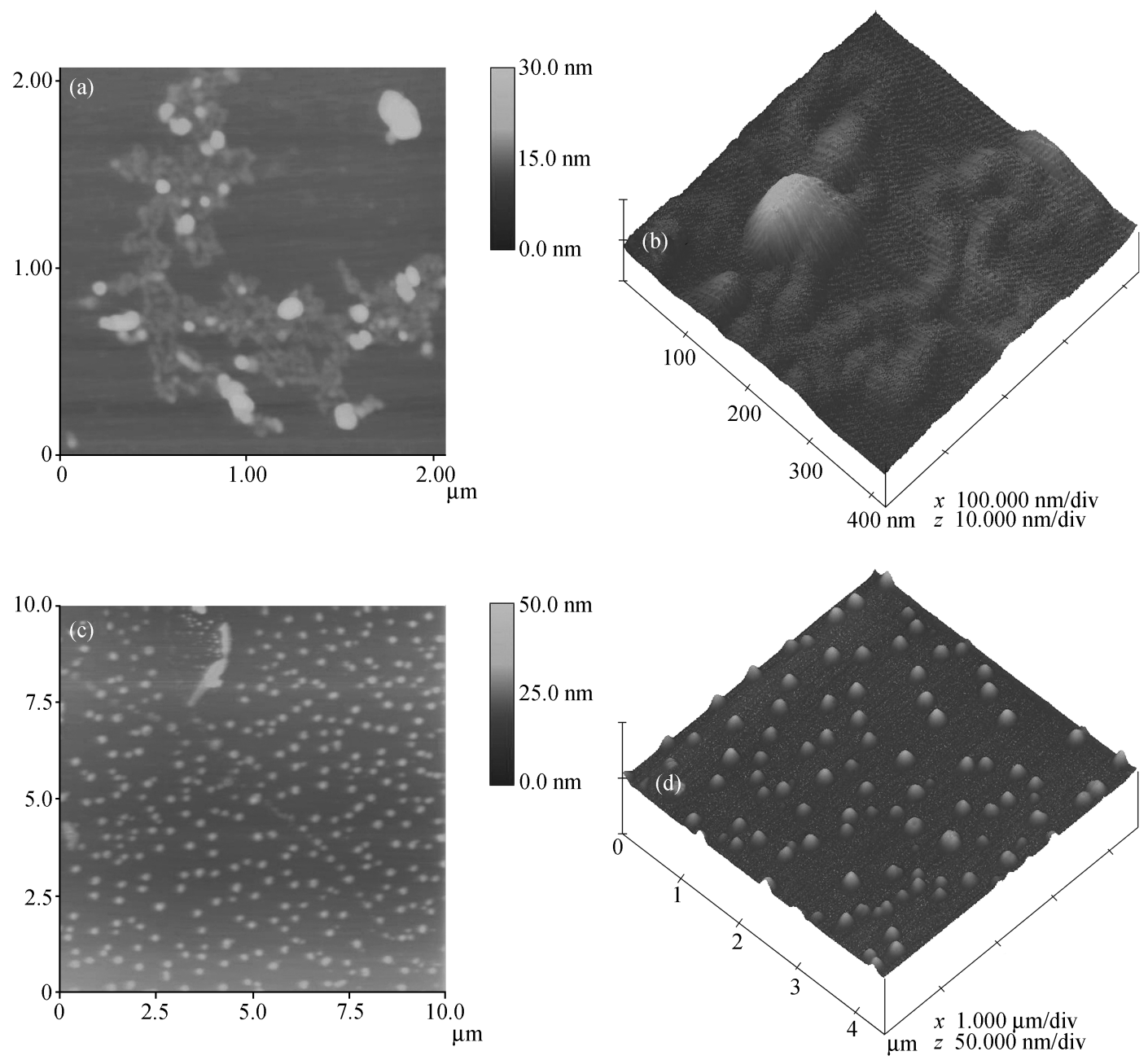

Fig. 1. AFM images showing the structural difference between Guanting and Tianjin humic samples at lower concentration (10 mg/L). (a) and (b) Topography of Guanting sample and its 3-D close-up of the irregular loop-chain assemblies with the chain width of c.a. $40 \mathrm{~nm}$; (c) and (d) topography of Tianjin sample and its 3-D close-up of the discrete spheroids with the diameter of $250-330 \mathrm{~nm}$.

the chain width of which is about $40 \mathrm{~nm}$ with a height of $0.5-1.0 \mathrm{~nm}$, while the Tianjin sample, however, was found to form more compact assembly structures of small discrete spheres with 250 to $330 \mathrm{~nm}$ in diameter and $8.6 \mathrm{~nm}$ in height. At higher concentrations (30 or $100 \mathrm{mg} / \mathrm{L}$, Fig. 2), both HA samples are shown to have multiple assembly structures, in which sponge-like structures, perforated sheets, aggregates of spheres, etc. are apparent. Compared with the compact structure of Tianjin humic sample, the heterogeneous and polydisperse features of Guanting humic substances are more evident, showing both loose and compact assemblies with a great variety, including sponge-like structures, branches, gel-like clumps etc. (Fig. 3). These morphological differences may attrib- ute to their different origin, composition and physicochemical nature.

As shown in Tables 1 and 2, a major difference is shown for their composition and the physicochemical properties. The Guanting sample gives a TOC content of $28.76 \%$ with the DOC value of $2.78 \%$, while the Tianjin humic substance, however, shows a higher TOC of $64.77 \%$ but much lower content of DOC (0.87\%). CPMAS ${ }^{13} \mathrm{C}$ NMR and ${ }^{1} \mathrm{H}$ NMR spectra provide further evidence on the functional group and structural composition of the two HS samples. The Guanting sample presents large N content $(2.97 \%)$ and high $\mathrm{O} / \mathrm{C}$ ratio $(0.79)$ with $\mathrm{H} / \mathrm{C}$ ratio of 1.98 , and the CPMAS ${ }^{13} \mathrm{C}$ NMR spectra show a high aliphatic and carboxylic carbon content $(55.9 \%$ and 15.0 , respec- 

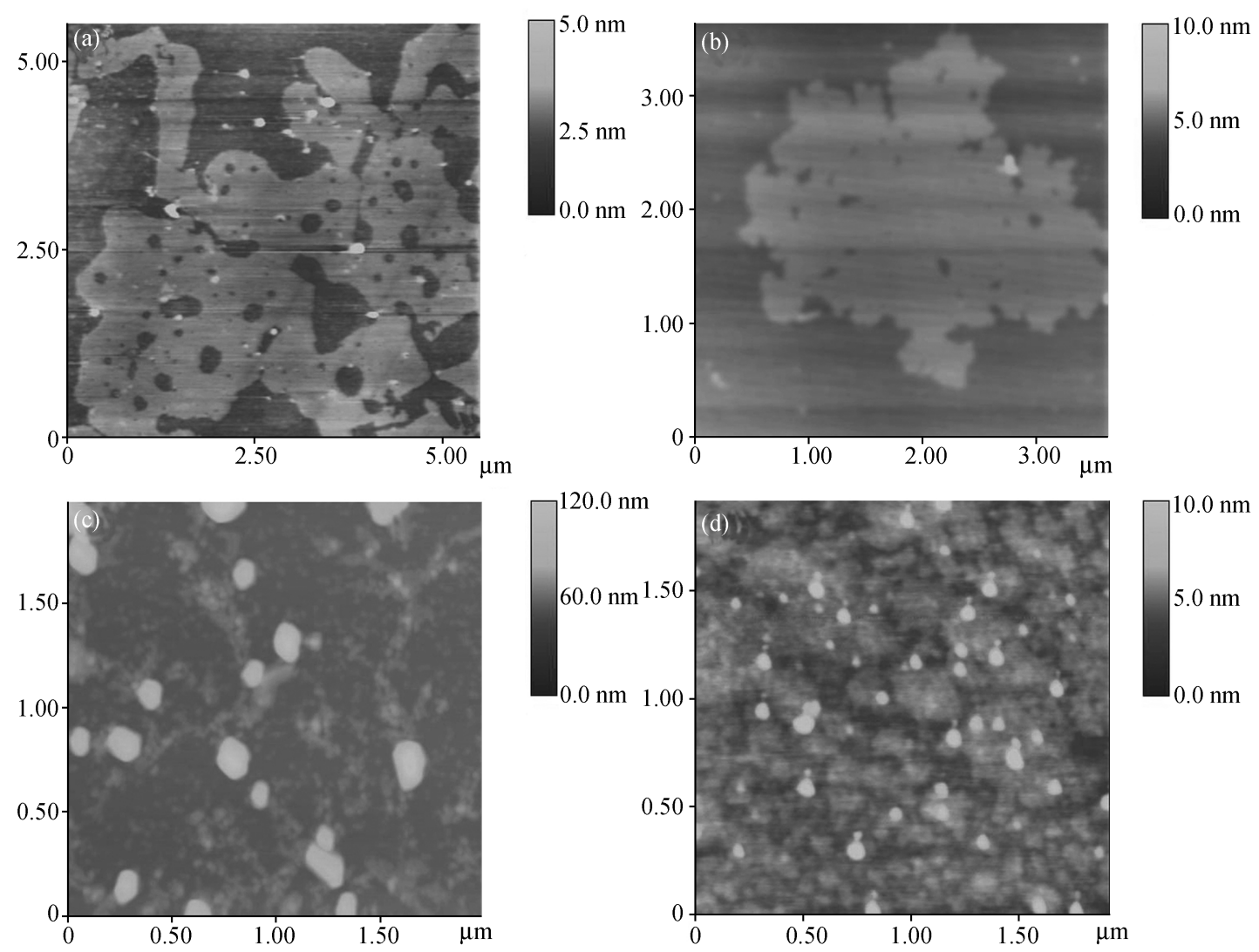

Fig. 2. AFM images of Guanting ((a) and (c)) and Tianjin ((b) and (d)) humic samples at higher concentrations ((a) and (b), $30 \mathrm{mg} / \mathrm{L} ;(\mathrm{c})$ and (d), $100 \mathrm{mg} / \mathrm{L}$ ). (a) and (b) Perforated sheet-like structures; (b) and (d) aggregated spheroids and globular clusters.

tively) with the relatively low aromatic and carbonyl carbon contents $(21.8 \%$ and $5.3 \%$, respectively), indicating that it is rich in polar groups and aliphatic compounds. The Tianjin humic substance, however, exhibits a high content of $\mathrm{C}(62.53 \%)$ with its $\mathrm{H} / \mathrm{C}$ ratio $(0.92)$ close to 1 and the $\mathrm{O} / \mathrm{C}$ ratio of 0.39 , and the CPMAS ${ }^{13} \mathrm{C}$ NMR spectra indicate a nearly equivalent amount of both aliphatic and aromatic carbon $(41.1 \%)$, very low carboxylic carbon $(2.5 \%)$ with the high carbonyl carbon of $12.4 \%$, implying a higher content of aromatic compounds and high content of low polar groups in the sample.

Since aliphatic and polar organic fractions constitute the majority of Guanting humic sample, these components have amphiphilic groups as in the molecular structure of surfactants, which may form micelle-like aggregates in solution and aggregate into various assembly structures at mineral surfaces. Fig. 3 presents morphologically more evidence on the heterogeneous and polydisperse features of Guanting humic sample, especially when higher HA concentrations are used. These results are in accordance with the above discussion about its structure and composition.

As shown in Fig. 4, Guanting humic sample was further examined for its morphological changes on mica under the coadsorption of naphthalene in order to investigate the interaction mechanism of humic substances in the sorption of naphthalene onto the natural particles. It is obvious that under the coadsorption of naphthalene the assemblies of humic substances clearly become more compact than those of the controlled sample blank without naphthalene, the chain width changing from $500-650 \mathrm{~nm}$ to $300-350 \mathrm{~nm}$ and the perforated sheet-like structure reducing from $1.5 \mu \mathrm{m}$ to $500 \mathrm{~nm}$ in width. Moreover, gel-like clumps were further observed for the naphthalene-incorporated sample. The aggregated branches become significantly narrowed down and the perforated sheet-like structures become less porous, implying that naphthalene molecules may form associates with the humic 

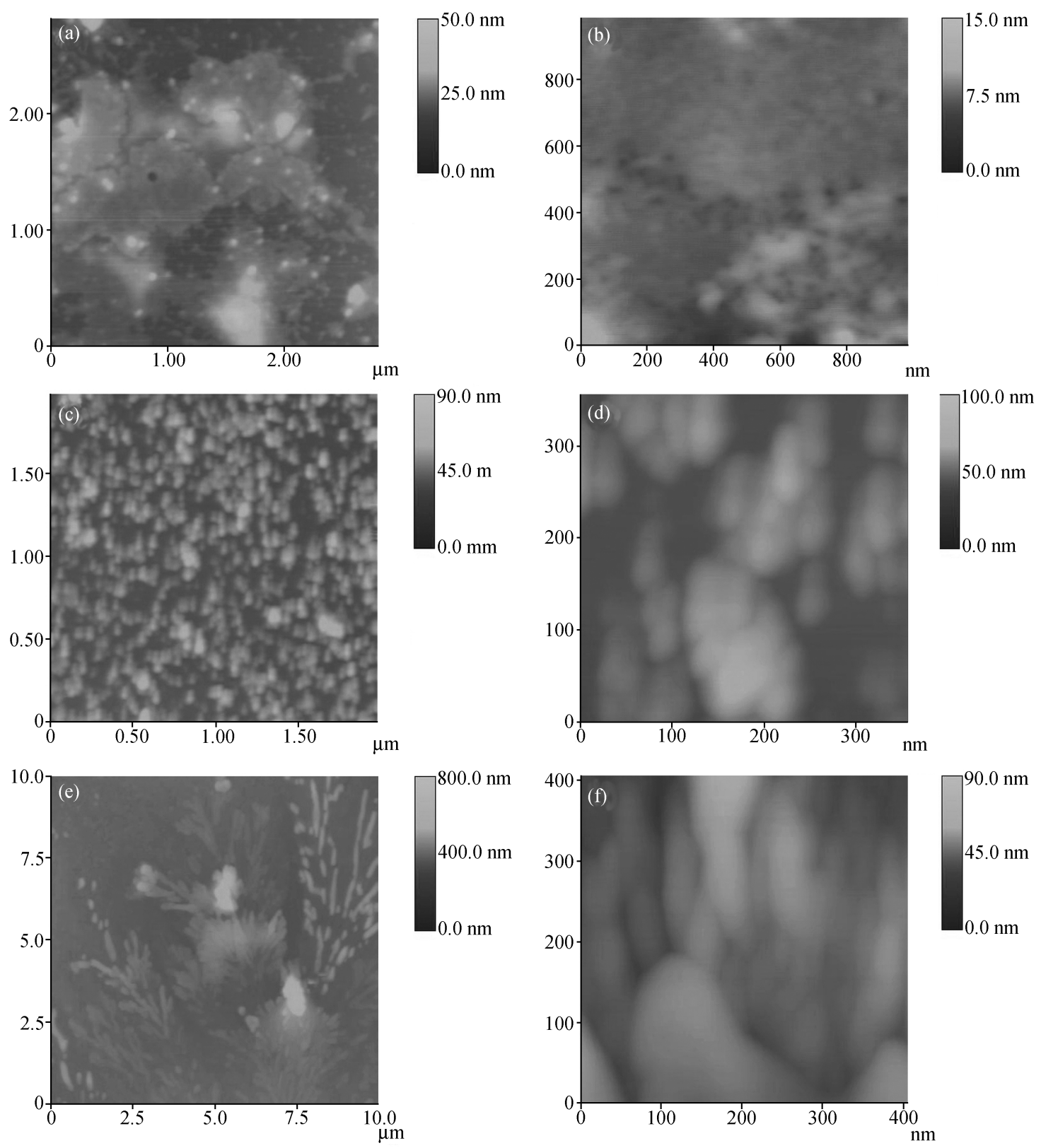

Fig. 3. Polydispersity of Guanting humic sample on mica at $100 \mathrm{mg} / \mathrm{L}$. (a) Gel-like clumps and micro flocs; (b) loosely assembled structures and sponge-like domains; (c) and (d) aggregated globular clusters and their close-up image, showing the tightly assembled structure of $50 \mathrm{~nm}$ in diameter and $8-15 \mathrm{~nm}$ in thickness; (e) and (f) branched chain-like structures and their close-up image, indicating the compact ribbon assembly or bundle of flattened filaments.

substances, reinforce connections between the HA molecules, and therefore cause the assembly structures to be more compact. It is indicative of that smaller nanometer-scale rings present along the circumstance in the perforated sheet-like assembly structures could potentially represent hydrophobic domains, which may alter the assembly structure via the hydrophobic interaction and therefore lead to an important role of dissolved humic substances in the sorption of environmental pollutants.

Despite much discrepancy in their complex molecular structures in the literature, humic substances have been substantiated to consist of separate hydrophobic and hydrophilic parts and form self-associating aggregates in solution by intermolecular hydrophobic interactions ${ }^{[20,41]}$. As amphiphilic polyelectrolytes, 

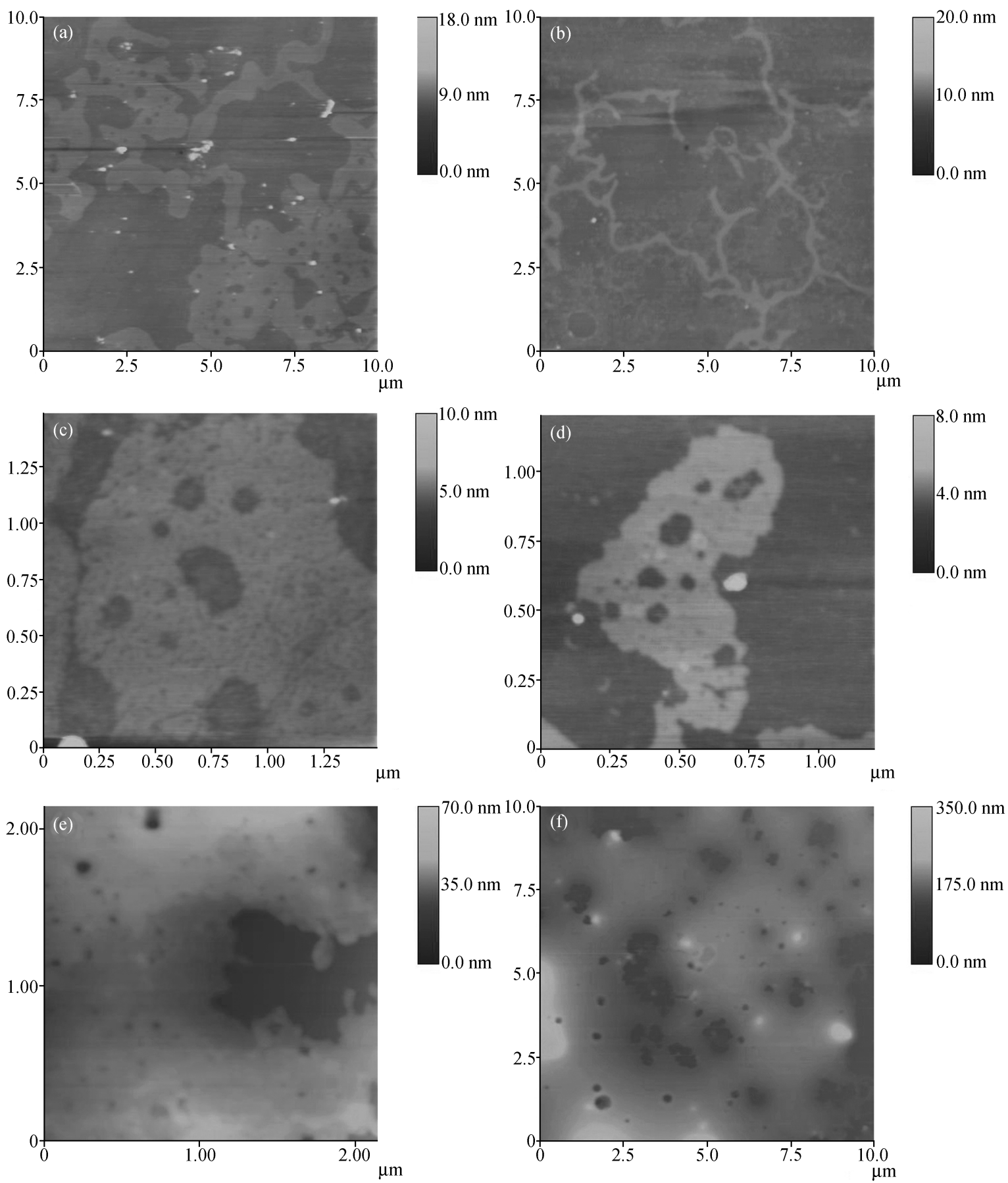

Fig. 4. Changes in the morphology of Guanting humic sample with the coadsorption of naphthalene (naphthalene, $30 \mathrm{mg} / \mathrm{L}$, right images of (b), (d) and (f); humic concentration, $30 \mathrm{mg} / \mathrm{L}$ ), showing that the aggregates of humic substances become more compact when naphthalene is introduced.

humic substances can be dissolved or precipitated in aqueous media, can accumulate at interfaces, can form self-assemblages, can exist in different colloidal states. Their morphology may not be permanently unchanged. Whether they take the form as flexible linear chains or as random coils in their molecular conformation, depend on their solution conditions, including the concentration of humic substances, solution $\mathrm{pH}$, ion strength or salinity, polyvalent metal ions ${ }^{[16,34,35]}$ and temperature as well. Hydrophobic organic contami- 
nants, such as naphthalene etc., have strong affinity toward the hydrophobic groups of the humic substances, and their adsorption onto the natural particles acts mainly on the organic layers of the natural particles. Therefore, earlier investigations ${ }^{[10,11,42-45]}$ showed that sorption of hydrophobic organic contaminants (HOCs) by soils and sediments is dominated by partitioning into relatively homogeneous, lipophilic, gel-like humic matrices, which can be recognized as a partition or dissolution process and has the linear adsorption features. A number of more recent studi$\mathrm{es}^{[12-15,46-55]}$, however, have indicated that such sorption often manifests substantial deviations from a linear partition model, provided that very low concentrations of HOCs are studied. In that case, a presumed adsorption process is often observed, as evidenced by the nonlinear, slow, hysteretic and competitive sorption behaviors. The overall sorption process of HOCs is distinctively shown to be biphasic, generally involves a fast initial uptake followed by a very slow sustained rate that may require periods of weeks or even months or years to reach apparent equilibrium ${ }^{[56]}$. It has been further hypothesized that sorption of HOCs by soils and sediments is highly dependent on the structure and chemical composition of associated humic substances at the microscopic scale, which may comprise two distinctly different types of domains: a soft, highly amorphous and swollen domain and a hard, relatively condensed and tightly knit domain. While the concept of two principal types of SOM domains appears quite reasonable as a basis for reconciling the non-partitioning-like behaviors exhibited by most soils and sediments, further experimental evidence on the morphology and structure of the two different domains is preferred. We have here investigated the sorption and aggregation behavior of dissolved humic substances on mica and presented direct evidence on the heterogeneity and polydispersivity of humic substances at interface. Furthermore, the comparative study on the sorption behavior of dissolved humic substances under the coadsorption of naphthalene indicates that dissolved humic substances may present the ring circumstances along the small pores inside the perforated sheet-like assemblies as the hydrophobic domains to form associates with HOCs, which makes the interaction between the HA molecules much stronger, and therefore causes the assembly structures to be more compact.

\section{Conclusion}

A major difference in the morphology has been identified for the two humic samples of Guanting and Tianjin. The Guanting HA was found to form irregular loop-chain assemblies of hundreds of nanometer in diameter, while the Tianjin HA showed small discrete spheres. Compared with the compact assembly of the Tianjin HA, the Guanting HA showed both loose and tight assemblages with a great variety at higher concentrations, which can be attributed to the more polar aliphatic fractions in the chemical composition in the latter.

With the coadsorption of naphthalene, assemblies of Guanting HA clearly become more compact, showing significantly narrowed branches and the perforated sheet-like structures being less porous. It is indicative of that naphthalene molecules may take up the smaller nanometer-scale rings present along the perforated assemblies as the hydrophobic domains to form associates with humic substances and cause the assembly to become more compact, which may facilitate the binding and transport of naphthalene onto the natural particles.

Acknowledgements The kind comments and suggestions by the anonymous reviewers are greatly appreciated. This research was supported by the National Natural Science Foundation of China (Grant Nos. 20037010 and 20277042).

\section{References}

1 Hayes M H B, Clapp C E. Humic substances: Considerations of compositions, aspects of structure, and environmental influences. Soil Science, 2001, 166(11): 723-737

2 MacCarthy P. The principles of humic substances. Soil Science, 2001, 166(11): 738-751

3 Swift R S. Macromolecular properties of soil humic substances: Fact, fiction, and opinion. Soil Science, 1999, 164(11): 790-802

4 Wershaw R L. Molecular aggregation of humic substances. Soil Science, 1999, 164(11): 803-813

5 Tombacz E. Colloidal properties of humic acids and spontaneous changes of their colloidal state under variable solution conditions. Soil Science, 1999, 164(11): 814-824

6 Tipping E, Higgins D C. The effect of adsorbed humic substances on the colloid stability of haematite particles. Colloid Surf, 1982, 5(2): 85-92 
7 Wilkinson K J, Nègre J C, Buffle J. Coagulation of colloidal material in surface waters: The role of natural organic matter. J Contam Hydrol, 1997, 26(1-4): 229-243

8 Garbarini D R, Lion L W. Influence of the nature of soil organics on the sorption of toluene and trichloroethylene. Environ Sci Technol, 1986, 20(12): 1263-1269

9 Gauthler T D, Seitz W R, Grant C L. Effects of structural and compositional variations of dissolved humic materials on pyrene KOC values. Environ Sci Technol, 1987, 21(3): 243-248

10 Chiou C T, Malcolm R L, Brinton T I, et al. Water solubility enhancement of some organic pollutants and pesticides by dissolved humic and fulvic acids. Environ Sci Technol, 1986, 20(5): 502-508

11 Chiou C T, Kile D E, Brinton T I, et al. A comparison of water solubility enhancements of organic solutes by aquatic humic materials and commercial humic acids. Environ Sci Technol, 1987, 21(12): $1231-1234$

12 Rutherford D W, Chiou C T, Kile D E. Influence of soil organic matter composition on partition of organic compounds. Environ Sci Technol, 1992, 26(2): 336-340

13 Grathwohl P. Influence of organic matter from soils and sediments from various origins on the sorption of some chlorinated aliphatic hydrocarbons: Implications on KOC correlations. Environ Sci Technol, 1990, 24(11): 1687-1693

14 Murphy E M, Zachara J M, Smith S C, et al. Interaction of hydrophobic organic compounds with mineral-bound humic substances. Environ Sci Technol, 1994, 28(7): 1291-1299

15 Huang W L, Weber W J Jr. A distributed reactivity model for sorption by soils and sediments. 10. Relationships between desorption, hysteresis, and the chemical characteristics of organic domains. Environ Sci Technol, 1997, 31(9): 2562-2569

16 Engebretson R R, von Wandruszka R. Kinetic aspects of cationenhanced aggregation in aqueous humic acids. Environ Sci Technol, 1998, 32(4): 488-493

17 Ghosh K, Schnitzer M. Macromolecular structures of humic substances. Soil Science, 1980, 129(5): 266-276

18 Camerson R S, Thomton B K, Swift R S, et al. Molecular weight and shape of humic acid from sedimentation and diffusion measurements on fractionated extracts. Journal of Soil Science, 1972, 23: $394-408$

19 Cornel P K, Summers R S, Roberts P V. Diffusion of humic acid in dilute aqueous solution. J Colloid Interface Sci, 1986, 110(1): $149-164$

20 Engebretson R R, von Wandruszka R. Microorganization in dissolved humic acids. Environ Sci Technol, 1994, 28(11): 19341941

21 Lobartini J C, Tan K H. Differences in humic acid characteristics as determined by carbon-13 nuclear magnetic resonance, scanning electron microscopy, and infrared analysis. Soil Sci Soc Am J, 1988, 52(1): 125-130

22 Hatcher P G, Dria K J, Kim Sunghwan, et al. Modern analytical studies of humic substances. Soil Sci, 2001, 166(11): 770-794

23 Zhou Y M, Liu R X, Tang H X. Kinetics study of aqueous sorp- tion of phenanthrene to humic acids and sediments. J Environ Sci, 2004, 16(3): 408-413

24 Chen Y, Schnitzer M. Scanning electron microscopy of a humic acid and of a fulvic acid and its metal and clay complexes. Soil Sci Soc Am J, 1976, 40(5): 682-686

25 Stevenson I L, Schnitzer M. Transmission electron microscopy of extracted fulvic and humic acids. Soil Science, 1982, 133(3): $179-185$

26 Paredes J I, Martínez-Alonso A, Tascón J M D. Application of scanning tunneling and atomic force microscopies to the characterization of microporous and mesoporous materials. Microporous Mesoporous Mat, 2003, 65(2-3): 93-126

27 Heil D, Sposito G. Organic matter role in illitic soil colloids flocculation (III): Scanning force microscopy. Soil Sci Soc Am J, 1995, 59(1): 266-269

28 Gerin P A, Dufrêne Y F. Native surface structure of natural soil particles determined by combining atomic force microscopy and X-ray photoelectron spectroscopy. Colloid Surf B-Biointerfaces, 2003, 28(4): 295-305

29 Namjesnik-Dejanovic K, Maurice P A. Atomic force microscopy of soil and stream fulvic acids. Colloid Surf A-Physicochem Eng Asp, 1997, 120(1-3): 77-86

30 Maurice P A, Namjesnik-Dejanovic K. Aggregate structures of sorbed humic substances observed in aqueous solution. Environ Sci Technol, 1999, 33(9): 1538-1541

31 Wilkinson K J, Balnois E, Leppard G G, et al. Characteristic features of the major components of freshwater colloidal organic matter revealed by transmission electron and atomic force microscopy. Colloid Surf A-Physicochem Eng Asp, 1999, 155(2-3): $287-310$

32 Balnois E, Wilkinson K J, Lead J R, et al. Atomic force microscopy of humic substances: Effects of $\mathrm{pH}$ and ionic strength. Environ Sci Technol, 1999, 33(21): 3911-3917

33 Plaschke M, Römer J, Klenze R, et al. In situ AFM study of sorbed humic acid colloids at different $\mathrm{pH}$. Colloid Surf A-Physicochem Eng Asp, 1999, 160(3): 269-279

34 Plaschke M, Römer J, Klenze R. Influence of europium (III) on the adsorption of humic acid onto mica studied by AFM. Surf Interface Anal, 2000, 30(1): 297-300

35 Plaschke M, Rothe J, Schäfer T, et al. Combined AFM and STXM in situ study of the influence of Eu(III) on the agglomeration of humic acid. Colloid Surf A-Physicochem Eng Asp, 2002, 197(1-3): 245-256

36 Liu A G, Wu R C, Eschenazi E, et al. AFM on humic acid adsorption on mica. Colloid Surf A-Physicochem Eng Asp, 2000, 174(1-2): 245-252

37 Liu Y, Wang Y X, Mo H J, et al. Effect of organic substrate on the formation of extracellular polymeric substrates in activated sludge. Environmental Chemistry (in Chinese), 2004, 23(3): $252-257$

38 Schnitzer M. Organic matter extraction. In: Page A L, ed. Methods of Soil Analysis. Part 2. 2nd ed. Madison: American Society of Agronomy, 1982. 581 
39 Zhou Y M. Sorption mechanisms of polycyclic aromatic hydrocarbons onto natural particles. Dissertation for the Doctoral Degree (in Chinese). Research Center for Eco-Environmental Sciences, 2003

40 Hendershot W H, Duquette M. A simple barium chloride method for determining cationic exchange capacity and exchangeable cations. Soil Sci Soc Am J, 1986, 50: 605-608

41 Conte P, Piccolo A. Conformational arrangement of dissolved humic substances: Influence of solution composition on association of humic molecules. Environ Sci Technol, 1999, 33(10): $1682-1690$

42 Karickhoff S W, Brown D S, Scott T A. Sorption of hydrophobic pollutants on natural sediments. Water Res, 1979, 13(3): 241248

43 Chiou C T, Porter P E, Schmedding D W. Partition equilibria of nonionic organic compounds between soil organic matter and water. Environ Sci Technol, 1983, 17(4): 227-231

44 Kile D E, Chiou C T, Zhou H D, et al. Partition of nonpolar organic pollutants from water to soil and sediment organic matters. Environ Sci Technol, 1995, 29(5): 1401-1406

45 Chiou C T, Mcgroddy S E, Kile D E. Partition characteristics of polycyclic aromatic hydrocarbons on soils and sediments. Environ Sci Technol, 1998, 32(2): 264-269

46 Chiou C T, Kile D E. Deviations from sorption linearity on soils of polar and nonpolar organic compounds at low relative concentrations. Environ Sci Technol, 1998, 32(3): 338-343

47 Kile D E, Wershaw R T, Chiou C T. Correlation of soil and sediment organic matter polarity to aqueous sorption of nonionic compounds. Environ Sci Technol, 1999, 33(12): 2053-2056

48 Chiou C T, Kile D E, Rutherford D W, et al. Sorption of selected organic compounds from water to a peat soil and its humic acid and humin fractions: Potential sources of the sorption nonlinearlity. Environ Sci Technol, 2000, 34(7): 1254-1258

49 Zhu L Z, Chen B L, Tao S, et al. Interaction of organic contaminants with mineral-adsorbed surfactants. Environ Sci Technol, 2003, 37(17): 4001-4006

50 Murphy E M, Zachara J M, Smith S C. Influence of mineral-bound humic substances on the sorption of hydrophobic organic compounds. Environ Sci Technol, 1990, 24(10): 15071516

51 McGinley P M, Katz L E, Weber W J Jr. A distributed reactivity model for sorption by soils and sediments. 2. Multicomponent systems and competitive effects. Environ Sci Technol, 1993, 27(8): $1524-1531$

52 Haggerty R, Gorelick S M. Multiple-rate mass transfer for modeling diffusion and surface reactions in media with pore-scale heterogeneity. Water Resour Res, 1995, 31(10): 2383-2400

53 Xia G S, Ball W P. Adsorption-partitioning uptake of nine low-polarity organic chemicals on a natural sorbent. Environ Sci Technol, 1999, 33(2): 262-269

54 Xia G S, Ball W P. Polanyi-based models for the competitive sorption of low-polarity organic contaminants on a natural sorbent. Environ Sci Technol, 2000, 34(7): 1246-1253

55 Xia G S, Pignatello J J. Detailed sorption isotherms of polar and apolar compounds in a high-organic soils. Environ Sci Technol, 2001, 35(1): 84-94

56 Weber W J Jr, Huang W L. A distributed reactivity model for sorption by soils and sediments. 4. Intraparticle heterogeneity and phase-distribution relationships under nonequilibrium conditions. Environ Sci Technol, 1996, 30(3): 881-888 